\title{
PHYSIOTHERAPY MANAGEMENT OF LOW BACK PAIN WITH SACROILIAC JOINT COMPONENT: A CASE REPORT
}

\section{ABSTRACT}

This report describes a clinical case of a 71 year old man with low back pain of sacroiliac joint component. Patient reported to a physiotherapy clinic with a complaint of right-sided low back pain below the level of both posterior dimples over the past 3 weeks prior to physiotherapy. Pain description was constant, sharp and stabbing with radiation to the groin, buttock and the posterior aspect of the right thigh.

Digital posterior-anterior pressure and symmetry tests of gilet, supine long sitting, standing flexion were performed. Patient underwent five sacroiliac pain provocation tests. Traditional therapies of cryotherapy, hydropak and ultrasound therapy with limited evidence were used in the acute phase. Lumbar mobilization, soft tissue mobilization and stretching were applied for a period of 10 weeks. Outcomes of treatment were assessed using tape measure, box numerical scale, Oswestry disability questionnaire, oxford muscle grading scale.

At the end of 10 weeks, patient had improvement in all symptoms of pain, muscle weakness, muscles tightness, limitation in spinal motion and functional ability. Findings on all provocative tests were negative.

Physiotherapy outcomes were improved through the use of conventional treatment. Evidence on physiotherapy management of patients with low back pain of sacroiliac joint component appears under reported. Patients presenting with low back pain should be routinely screened for sacroiliac joint component. Physiotherapists are encouraged to report their findings so as to strengthen the available evidence.

\section{KEYWORDS: LOW BACK PAIN, SACROILIAC DYSFUNCTION, PHYSIOTHERAPY, DIAGNOSIS}

\section{INTRODUCTION}

Diagnosing the cause of back pain is often a difficult and challenging task because many structures in the back region have the potential to cause pain (Manchikanti et al, 2001). An accurate diagnosis is of paramount importance in the provision of effective treatment. The sacroiliac joint (SIJ) has been implicated as a source of low back and lower extremity pain (Rupert et al, 2009). Mechanical dysfunction, inflammation, infection, trauma and degeneration are all possible pathologies of the SIJ. According to Cohen (2005), the SIJ is a real, yet under appreciated pain generator in an estimated $15 \%$ to $25 \%$ of patients with axial Low Back Pain (LBP). Owing to the complexity of the joint, the mechanisms of SIJ pain are numerous and ill-defined.

Sacroiliac joint disease usually presents with lower back pain that increases with ambulation. Pathology of this joint is an often-overlooked part of the differential diagnosis of low back pain and sciatica. There is no universally accepted gold standard for the diagnosis of low back pain originating from the sacroiliac joint (Rupert et al, 2009). It is documented that there is paucity of literature on therapeutic interventions, variations in technique, and variable diagnostic standards for sacroiliac joint pain (Hansen et al, 2012). Many interventions have been reported in literature on the treatment of sacroiliac joint dysfunction especially manual therapy (Hansen et al, 2012; Laslett, 2008). These interventions include manipulation, acupuncture, prolotherapy, corticosteroid and intraarticular injections, stabilization exercises and physiotherapy (Hansen et al, 2012; Laslett, 2008). Many physiotherapists are aware and have been taught to consider sacroiliac joint dysfunction as a cause for low back pain, yet physiotherapy interventions in this regard appears to be under reported. Physiotherapists play a major role in the management of low back pain (Rundel et al, 2009), however it appears there is dearth of evidence on physiotherapy management of low back pain with sacroiliac joint component (Cilbuka, 1992; Cilbuka et al, 1988). Hence, a need to document this case report which describes the physiotherapy management of a patient who presented with a sacroiliac joint component to low back pain.

\section{Corresponding Author:}

Adesola C. Odole

Department of Physiotherapy,

College of Medicine,

University of Ibadan.

Nigeria

Email: adesola_odole@yahoo.com

25665219@nwu.ac.za 


\section{CASE DATA}

A 71-year-old physically active business man/pharmacist referred to physiotherapy with a complaint of rightsided low back pain. On the first day of presentation, he perceived his low back pain as severe. The pain was subjectively described as constant, sharp and stabbing, radiating to the groin, buttock and the posterior aspect of the right thigh. He also described the pain as a dull ache around the right dimple and reported waking up with right-sided low back pain for the past week. There was no history of trauma or injury to his low back. Activity limitations were presented as difficulty in changing posture from sitting to standing and his preferred sleeping posture was in the prone-lying position with the right knee flexed and hip laterally rotated. At the onset of pain, patient was on self-medication of nonsteroidal anti-inflammatory drugs which seemed to relieve his pain for the first five days before seeking medical attention after aggravation of his symptoms. Pain had been present for about two weeks before presentation at the hospital. He had consulted several medical practitioners in the past for these complaints. Plain radiograph of the lumbar spine revealed reduced intervertebral disc spaces and straightening of the spinal column at L4-S1. A diagnosis of lumbar spondylosis was made by his physician with subsequent referral for physiotherapy.

\section{PHYSICAL EXAMINATION AND ASSESSMENT}

At first presentation for physiotherapy, the patient walked with a right antalgic gait and a listing towards the right side. He was supported into the treatment

\section{Table 1: Description of the Symmetry tests}

\begin{tabular}{|l|l|}
\hline Test & Description \\
\hline Gilet & $\begin{array}{l}\text { Patient stood on the right lower extremity and flexed } \\
\text { the left hip and Knee toward the chest. Examiner } \\
\text { palpated for movement of the sacral sulcus and PSIS }\end{array}$ \\
\hline Supine long sitting & $\begin{array}{l}\text { Patient moved from a supine position to long sitting } \\
\text { position. Examiner palpated patient's medial malleoli }\end{array}$ \\
\hline Standing flexion & $\begin{array}{l}\text { Patient flexed the trunk in standing. Examiner } \\
\text { palpated for movement of the PSISs }\end{array}$ \\
\hline
\end{tabular}

room by his wife with his hand placed at the right side of his waist. The patient complained of pain at his lower waist and buttocks with the right side being more painful. Visual observation of the patient in standing (while holding onto the parallel bars) showed a mild deformity of the lumbar spine in the frontal or sagittal plane and apparent asymmetry of the lower limbs. Active spinal motion visually assessed, was painful, and he could not touch his toes (right) with right knee completely extended. He also reported "tightness" in the low back upon returning from forward bending. The high lumbar flexion motion showed evidence of muscle guarding. High lumbar extension was painful only at end range of motion. High lateral flexion was full and pain free for the left but limited to the middle range - (measurement was taken using a tape measure from the tip of the middle finger to the floor) and painful at the low back for the right. Laseque's test was positive with pain at the right side of the low back at 550 on the right lower limb and tightness of the $\mathrm{m}$. hamstring. Right hip and knee flexion movements or ranges were carried out passively on the patient and this revealed a tightness of the right $\mathrm{m}$. quadriceps. Ely's test was positive on the right lower limb. Palpation of the posterior superior iliac spines (PSIS) and anterior superior iliac spines (ASIS) were done bilaterally. the right ASIS appeared higher,while the right PSIS appeared lower. Symmetry tests with Gilet test, supine long sitting test, standing flexion test revealed a change of about $1.2 \mathrm{~cm}$ in the lengths of the lower extremities confirming that innominate bone rotation was present. A description of these tests is presented in table 1. In supine-lying, ACO (first author) took limb length measurements using a tape measure from the ASIS to the malleoli bilaterally and a limblength discrepancy of one centimetre was noted. The patient underwent five sacroiliac pain provocation tests (table 2), which included the distraction test, compression test, sacral thrust test, Gaenslen's test and Patrick's test. Patient reported positive findings on four tests, except the distraction test. Physical diagnosis of LBP with SIJ origin was arrived at based on the findings from the provocation tests. There was no impairment of neurological conduction of the patient in the lower limbs. Digital (posterior to anterior) pressure to the spinous process of the lumbar and sacral spines elicited pain on the fifth lumbar vertebrae and the first and second sacral vertebrae (patient rated the tenderness as $4 / 10$ on the box numerical pain rating scale). There was tenderness on palpation of the region medial to the right PSIS (patient rated the tenderness as $7 / 10$ on the box numerical pain rating scale). There was tightness of the m. quadriceps femoris and the $\mathrm{m}$. hamstring. The initial muscle assessment on the right lower limb could not be done because of the severe pain experienced by the patient.

His low back pain score on the box numerical pain rating scale was 8/10. Patient's ratings on other painful regions are presented in table 3. Functional ability was assessed using the Oswestry low back pain disability questionnaire and the patient had a score of 36 at baseline. The Oswestry questionnaire measures perceived disability with a score ranging from 0 to 100 . After three sessions of therapeutic interventions by ACO, manual muscle testing was carried out on both lower limbs. All muscles showed normal grade and pain free except for the right $\mathrm{m}$.hamstring and $\mathrm{m}$. quadriceps with grade power 3 according to the oxford muscle grading. The clinical outcomes that were assessed were pain at the low back, right hip, groin and region medial to the right PSIS, muscle tightness of the right $\mathrm{m}$. quadriceps and $\mathrm{m}$. hamstring, muscle power of the right $\mathrm{m}$. quadriceps and $\mathrm{m}$. hamstring, functional ability, spinal motions, limb length discrepancy. All these clinical outcomes are presented in Table 3.

\section{TREATMENT}

The patient was treated conservatively at the initial phase of therapy with the use 
of cryotherapy, hydropak, ultrasound and soft tissue manipulations (massage). Though the empirical evidence base to support the common practice of superficial heat and cold for low back pain is limited, there is moderate evidence in a small number of trials that hydropak therapy provides a small short-term reduction in pain and disability in a population with a mix of acute and sub-acute low back pain (French et. al., 2006). Anecdotally, cryotherapy and hydropak therapy have been reported to reduce pain and disability in patients with pain intensity $>6 / 10$ on the visual analogue scale. Cryotherapy was applied to the patient's right hip, right groin regions and the tender region medial to the right PSIS for 15 minutes daily to relief pain during the acute high intense pain frame of one week followed by three weekly sessions for another week. Patient could not tolerate any form of exercises at this stage. Therapeutic ultrasound within the intensity range $0.1-2.5 \mathrm{~W} / \mathrm{cm} 2$ is used widely in the treatment of musculoskeletal conditions (Maher, 2004). The treatment can be delivered as a single treatment or more commonly as an adjunct to other physical treatment (Maher, 2004). We applied pulsed ultrasound $(3 \mathrm{MHz}$ at $0.75 \mathrm{~W} / \mathrm{cm} 2$ for 5 minutes) three times a week for three weeks to the tender region medial to the right PSIS after the two weeks of cryotherapy. The patient also received soft tissue manipulations to all painful regions after the first week with the use of a topical non-steroidal anti- inflammatory gel. Patient was only able to tolerate soft tissue manipulation after moderate reduction in pain intensity which was achieved after two weeks of cryotherapy. Although, there is limited evidence of the use of exercise in the management of low back pai treatment for chronic LBP, the optimal way to implement this treatment is unknown (Maher, 2004). Massage has been reported as a stand-alone treatment or as part of a treatment package in the management of low back pain (Maher, 2004), though not specific to LBP with sacroiliac joint component. Exercises and spinal manipulations improve outcomes of pain and disability in patients with low back pain of sacroiliac joint component (Maher, 2004). Literature has not provided evidence on specific forms of exercises in the management of low back pain with sacroiliac joint component. Because of uncertainty

Table 2: Description of the five Sacroiliac Pain Provocation Tests

\begin{tabular}{|l|l|}
\hline Test & Description \\
\hline Distraction & $\begin{array}{l}\text { The examiner with arms crossed over, applied a } \\
\text { medially directed pressure over the ASIS with the } \\
\text { patient in supine-lying position }\end{array}$ \\
\hline Compression & $\begin{array}{l}\text { The examiner applied a vertically directed pressure } \\
\text { directed at the iliac crest in with the patient in side- } \\
\text { lying position }\end{array}$ \\
\hline Sacral Thrust & $\begin{array}{l}\text { The examiner applied a vertically directed force on the } \\
\text { midline of the sacrum at the apex of the curve of the } \\
\text { sacrum with the patient in prone lying position }\end{array}$ \\
\hline Gaenslen's & $\begin{array}{l}\text { Patient in supine, tested hip and knee flexed to } 90 \\
\text { degrees, examiner applied a Superior/posterior force } \\
\text { on tested knee and a posteriorly directed force on the } \\
\text { opposite knee }\end{array}$ \\
\hline Patrick & $\begin{array}{l}\text { Patient's right hip was flexed to 90 degrees, abducted } \\
\text { and laterally rotated in the supine lying position by } \\
\text { the examiner. A simultaneous posterior pressure was } \\
\text { applied to the medial aspect of right knee and left } \\
\text { ASIS }\end{array}$ \\
\hline
\end{tabular}

about the best way to prescribe exercise, an enormous variety of exercise programs currently are offered to of low back pain with sacroiliac joint component patients (Maher, 2004). The most commonly prescribed exercises include those aimed at retraining m.multifidus and $\mathrm{m}$. transverses abdominus (Maher, 2004). Back extension exercises with end range stretch sustained for four seconds with five repetitions were carried out three times a week throughout the third and fourth weeks. Active knee to chest stretching exercises were also carried out on the contralateral limb in supine position to stretch the affected. m.hamstring throughout the period of treatment (five repetitions, three times a week). Passive muscle stretches were also applied to the patient's right $\mathrm{m}$. quadriceps in left side-lying position, by extending the ipsilateral hip, flexing the knee, and maintaining the position for 30 seconds (five repetitions, three times a week). After two weeks of cryotherapy, the patient received hydropak to the right hip and groin region for 15 minutes three times a week for another 3 weeks. Treatment sessions were reduced to once weekly till point of discharge after the three weeks. Lumbar rotation exercises (five repetitions, three times a week) with patient in side lying position was applied after the first two weeks of therapy.

The back extension exercises and active stretching exercises were incorporated as home programme for the patient on a daily basis. Patient received therapy for a period of 10 weeks after which he was discharged and encouraged to carry out his home programme which was monitored by the wife who acted as an informal caregiver. Feedback was received through telephone calls.

\section{OUTCOMES OF TREATMENT}

After the two weeks sessions of cryotherapy, right antalgic gait was barely noticeable; patient reported a decrease in low back pain intensity from eight to five and from eight to four at the hip using the box numerical scale (table 3 ). The range of high lumbar flexion was increased and the patient was able to touch his toes with the right knee extended. Range of trunk motions is presented in table 3. After four weeks of treatment, there was an appreciable decrease in the patient's symptoms. The patient reported a decrease in pain intensity at the tender region medial to the right PSIS from seven to two out of ten (table 3 ). The 3 symmetry tests (ie, gilet, supine long sitting, and standing flexion test) were repeated to determine whether innominate bone rotation was still present. After four sessions of lum- 
Table 3: Clinical Outcomes Assessed during treatment

\begin{tabular}{|c|c|c|c|c|c|c|c|}
\hline \multicolumn{2}{|c|}{ Clinical Outcome } & \multicolumn{6}{|c|}{ Treatment period (weeks) } \\
\hline & & Baseline & 2 & 4 & 6 & 8 & 10 \\
\hline \multicolumn{2}{|l|}{ Muscle } & \multicolumn{6}{|l|}{ Strength } \\
\hline \multirow[t]{4}{*}{ Hamstring } & Left & * & 5 & 5 & - & 5 & 5 \\
\hline & Right & * & 3 & 3 & - & 4 & 5 \\
\hline & Left & * & 5 & 5 & - & 5 & 5 \\
\hline & Right & * & 3 & 3 & - & 5 & 5 \\
\hline \multirow[t]{6}{*}{ Pain } & Hip & 8 & 4 & 3 & - & 1 & 1 \\
\hline & Groin & 6 & 3 & 4 & - & 1 & 0 \\
\hline & Low Back & 8 & 5 & 4 & - & 1 & 0 \\
\hline & $\begin{array}{l}\text { Medial to } \\
\text { Right PSIS }\end{array}$ & 7 & 4 & 2 & - & 0 & 0 \\
\hline & $\begin{array}{l}\text { Right side } \\
\text { flexion }\end{array}$ & 6 & 4 & 2 & - & 0 & 0 \\
\hline & $\begin{array}{l}\text { Back } \\
\text { extension }\end{array}$ & 3 & 1 & 1 & - & 0 & 0 \\
\hline $\begin{array}{l}\text { Functional } \\
\text { ability }\end{array}$ & & 36 & 32 & 24 & - & 10 & 10 \\
\hline \multirow[t]{2}{*}{$\begin{array}{l}\text { Spinal } \\
\text { Motion }\end{array}$} & $\begin{array}{l}\text { Forward } \\
\text { Flexion }\end{array}$ & * & $42 \mathrm{~cm}$ & - & - & $28 \mathrm{~cm}$ & $25 \mathrm{~cm}$ \\
\hline & $\begin{array}{l}\text { Side Flexion } \\
\text { (right) }\end{array}$ & * & $48 \mathrm{~cm}$ & - & - & $39 \mathrm{~cm}$ & $38 \mathrm{~cm}$ \\
\hline \multirow[t]{5}{*}{ Limb } & Length & Measurement & & & & & \\
\hline & $\begin{array}{l}\text { Apparent } \\
\text { (left) }\end{array}$ & $102 \mathrm{~cm}$ & - & - & - & - & $102 \mathrm{~cm}$ \\
\hline & Real & $88 \mathrm{~cm}$ & - & - & - & - & - \\
\hline & $\begin{array}{l}\text { Apparent } \\
\text { (right) }\end{array}$ & $101.2 \mathrm{~cm}$ & - & - & - & - & $102 \mathrm{~cm}$ \\
\hline & Real (right) & $88 \mathrm{~cm}$ & - & - & - & - & - \\
\hline \multirow[t]{2}{*}{$\begin{array}{l}\text { Muscle } \\
\text { Tightness }\end{array}$} & Hamstring & severe & - & - & - & mild & nil \\
\hline & Quadriceps & severe & - & - & - & mild & nil \\
\hline $\begin{array}{l}*=\text { could no } \\
-=\text { assessme }\end{array}$ & $\begin{array}{l}\text { be assessed } \\
\text { was not as }\end{array}$ & cause of pain & in & 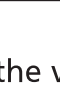 & & & \\
\hline
\end{tabular}

bar rotation manipulative technique, all four tests showed no evidence of innominate bone rotation. In addition, the patient reported no pain during all five sacroiliac pain provocation tests. No leg length discrepancy could be detected by comparing the heights of the ASISs in supine. By the end of the 10 weeks of physiotherapy, all symptoms (pain, tenderness, muscles tightness, limitation in spinal motion, limb length discrepancy) were relieved except for mild occasional pain $(1 / 10)$ at the right hip. Patient's rating on the Oswestry low back pain disability questionnaire had improved from 36 (moderate disability) to 10 (mild disability). The clinical outcomes throughout the 10-weeks period of treatment are presented in table 3 .

\section{DISCUSSION}

This study was aimed at documenting the findings of a clinical case in a 71 year old man diagnosed with low back pain of sacroiliac joint component who was managed using conventional physiotherapy treatment programme. It appears that treatment in a few physiotherapy departments is still based on intuition rather than on evidence especially when there is little or no published evidence. The use of evidence in clinical practice cannot be overemphasised. It is important to note that there are both qualitative and clinical or quantitative evidence. An attempt has been made to interrogate qualitative evidence from patient's feedback and quantitative or empirical evidence (on efficacy of the modalities) in this case.

There is no universally accepted gold standard for diagnosis of LBP of SIJ origin (Rupert et al, 2009). Physiotherapists often use physical tests in arriving at a physical diagnosis of SIJ dysfunction. The clinical usefulness of a cluster of sacroiliac joint tests utilised to arrive at a physical diagnosis of SIJ dysfunction has been reported (Laslett, 2008). In the present environment, it appears that many physiotherapists do not document their diagnostic procedure in the management of low back pain with sacroiliac joint component. From the clinical experience of one of the authors (ACO)and based on personal communication with physiotherapists, many physiotherapists go through the diagnostic process but do not often document this process. In this study, physical diagnosis of low back pain with sacroiliac joint component was hypothesised on palpation, application 
of digital pressure and a cluster of five sacroiliac joint provocative tests. The fact that the patient in this clinical case reported his primary low back pain at the level below the fifth lumbar vertebrae supports the likelihood of his pain to have its origin from the SIJ. Hancock et al. (2007) reported that in most studies investigating low back pain of sacroiliac origin, patients complained that their primary pain was below the level of the fifth lumbar vertebrae.

Physiotherapy management of low back pain is well documented in literature (Madigan et al, 2009; Rundel et al, 2009), with fewer studies reporting physiotherapy management of low back pain with SIJ component. There are no treatment guidelines in the management of low back pain with SIJ component hence comparisons can only be made with the few published studies. The aim of this report is to stimulate further research on the physiotherapy management of low back pain with a sacroiliac joint component, specifically randomised clinical trials. In our opinion, there are few studies that have examined the efficacy, efficiency and therapeutic value of physiotherapy in the management of patients with low back pain with a sacroiliac joint component. This study is an initial step at providing evidence in the successful management of a patient with low back pain with a sacroiliac joint component.

There are significant variations in the application of various techniques as well as a paucity of literature in the treatment of sacroiliac joint dysfunction (Hansen et al, 2012). There appears to be no clearcut evidence based physiotherapy guidelines in the treatment of low back pain with sacroiliac joint dysfunction. Such guidelines should be used with consideration for our clinical reasoning skills. Existing evidence appears inconclusive. We decided to treat this patient with conventional physiotherapy treatment based on non-empirical reports from patients that conventional management has led to improved patient-centred outcomes. In our opinion, we decided to investigate the efficacy of this treatment and provide empirical findings in this regard. Physical therapy strategies emphasize manual correction of SIJ asymmetry, lumbo-pelvic stabilization, and correction of muscle imbalance. However, outcome data following management of SIJ dysfunction are limited (Zelle et al, 2005) and, to our knowledge, randomized clinical trials comparing different treatment methods have not been reported. These include the use of muscle-energy techniques, exercises, mobilization, manipulation and soft tissue techniques. Exercise is one of the few treatments for chronic LBP that has been shown to have a large treatment effect in the short and long term. The optimal way to implement this treatment is unknown and consequently an enormous variety of exercise programs currently are offered to patients (Maher, 2004). This study involved a variety of exercise programs. Cilbuka, (1992) reported a successful treatment of a patient who had low back pain with a sacroiliac component by manipulating the sacroiliac joint, then restoring symmetrical hip rotation and eliminating extreme unilaterally rotated hip postures. Different forms of exercise therapy in the management of patients with LBP are seldom used by physiotherapists in clinical practices. The reasons for this seldom use of exercise therapy range from lack of understanding of its efficacy and evidence to high out-patients to therapist ratio. Most of the time therapists rush treatment regimen in order to attend to all out- patients and the modality that is often ignored is exercise therapy component. Literature supports the use of spinal manipulation therapy in the management of low back pain (Bronfort et al, 2008) though there are inconclusive reports within the subgroup of those with LBP with sacroiliac joint origin. Herzog et al, (1999) followed a series of 11 patients who were treated with spinal manipulations three times per week over a two-week period. Pain, joint mobility, and the Oswestry score improved in most patients until the end of the treatment. This case further emphasises the importance and need for joint mobilisation in the management of patients with LBP of SIJ origin.

The physiologic basis for improvement following mobilization and/or manipulation to the SIJ is unknown. A roentgen stereophoto-grammetric analysis study evaluated osseous positions before/after SIJ manipulation in 10 patients with presumed SIJ pain. There was no positional changes seen of the sacrum or ilium following manipulation of the SIJ to suggest an objective mechanical change occurs with manipulation (Tullberg et al, 1998). Future clinical trials should investigate efficacy of treatment in well-defined subgroups of LBP patients with a sacroiliac joint component according to validated and reliable diagnostic classification criteria. The improvement in treatment outcomes in the clinical case reported in this study needs to be further investigated. We believe that reporting the case report's findings could add to the data base of evidence from a developing country where there are seemingly few publications on the physiotherapy management of patients with low back pain with a sacroiliac joint component. Existing evidence in the physiotherapy management of this condition needs to be further proven.

\section{CONCLUSION}

This case report described improvement in outcomes following the treatment of a patient who had low back pain with a sacroiliac joint component, though treatment interventions which has little, moderate or no evidence. Existing evidence on treatment of low back pain with sacroiliac joint origin needs to be further investigated. More case studies should be reported by physiotherapists in order to provide stronger evidence in the management of these symptoms. Standardised treatment protocols should be developed in the management of low back pain with a sacroiliac joint component while incorporating our clinical reasoning skills for effective clinical decisions.

\section{LIMITATIONS}

The usefulness of provocative tests in clinical practice, particularly for guiding diagnosis of sacroiliac joint dysfunction and treatment selection appears unclear. The accuracy of the diagnosis of LBP with a sacroiliac joint origin could have been better with the use of computer tomography and magnetic resonance imaging. However, this study was exclusively based on physical diagnosis which does not involve the use of invasive techniques. The study is a case report on an individual patient, hence treatment cannot be generalised. It is recommended that future research should be directed at providing more empirical findings on the physiotherapy management of low back pain with a sacroiliac joint component through randomised clinical trials. 


\section{REFERENCES}

Bronfort G, Haas M, Evans R, Kawchuk G, Dagenais S 2008 Evidence-informed management of chronic low back pain with spinal manipulation and mobilization. The Spine Journal 8: 213-225

Cibulka MT, Delitto A, Koldehoff RM 1988 Changes in innominate tilt after manipulation of the sacroiliac joint in patients with low back pain: an experimental study. Physical Therapy 68:1359-1363.

Cibulka MT 1992 The treatment of the sacroiliac joint component to low back pain: a case report. Physical Therapy 72:917-922.

Cohen, 2005 Sacroiliac joint pain: a comprehensive review of anatomy, diagnosis, and treatment. Anaesthesia and Analgesia 101:1440-1453

Dontigny RL 1990 Anterior dysfunction of the sacroiliac joint as a major factor in the etiology of idiopathic low back pain syndrome. Physical Therapy 70:250-265.

French SD, Cameron M, Walker BF, Reggars JW, Esterman AJ 2006 A Cochrane review of superficial heat or cold for low back pain. Spine 31:998-1006.
Hancock MJ, Maher CG, Latimer J, Spindler MF, McAuley JH, Laslett M, Bogduk N. 2007 Systematic review of tests to identify the disc, SIJ or facet joint as the source of low back pain. European Spine Journal 16:1539-50. Epub 2007 Jun 14. DOI: 10.1007/ s00586-007-0391-1

Hansen H, Manchikanti L, Simopoulos TT, Christo PJ, Gupta S, Smith HS, Hameed H, Cohen SP 2012 A systematic evaluation of the therapeutic effectiveness of sacroiliac joint interventions. Pain Physician 15:E247-278.

Herzog W, Scheele D, Conway PJ1999 Electromyographic responses of back and limb muscles associated with spinal manipulative therapy. Spine24: 146-152

Laslett M 2008, Evidence-Based Diagnosis and Treatment of the painful Sacroiliac Joint: A Clinical Perspective. Journal of Manual and Manipulative Therapy 16: 142-152

Maher CG 2004, Effective physical treatment for chronic low back pain. Orthopaedic Clinics of North America 35: 57- 64

Manchikanti L, Singh V, Pampati V, Damron K, Barnhill R, Beyer C, Cash K 2001 Evaluation of the relative contributions of various structures in chronic low back pain. Pain Physician 4:308-316.

Merskey H, Bogduk N 1994 Classification of chronic pain: descriptions of chronic pain syndromes and definitions of pain terms. 2nd ed. IASP Press, Seattle

Rupert MP, Lee M, Manchikanti L, Datta S, and Cohen SP (2009), Evaluation of Sacroiliac Joint Interventions 2009: A Systematic Appraisal of the Literature Pain Physician: 12:399-418

Rundell SD, Davenport TE, Wagner T 2009 Physical Therapist Management of Acute and Chronic Low Back Pain Using the World Health Organization's International Classification of Functioning, Disability and Health Physical Therapy $89: 82-90$

Tullberg, T Bloomberg S, Branth B. JohnssonR. 1998 Manipulation does not alter the position of the sacroiliac joint: a roentgen stereophotogrammetric analysis. Spine. 23:1124-1129.

Zelle B A, Gruen G S, Brown S, George S 2005 Sacroiliac Joint Dysfunction Evaluation and Management. Clinical Journal of Pain 21:446-455 